she was at 'Trinidad, both caught the fever and died. One died on board the Calypso, and the other on shore; but in neither instance did the disease spread to other persons.

The cases now cited are very instructive as far as they go; but it is not upon two or tbree or half-a-dozen of such examples that I would seek to las down hastily or peremptorily any plan of sanitary police, altogether at variance certainly with that which the quarantine authorities of this country have recently adopted at Southampton; only, let the subject be fairly and fully looked into. Meanwhile let us have more facts and authenticated narratives respecting other vessels on board of which yellow fever has existed; and more particularly let information be obtained in reference to that most important practical point of the inquiry - viz., the results which have followed the landing of the crew upon the arrival of an infected ship, whether they be confirmatory or otherwise of the preceding statements. If this point were more steadily kept in view there would be infinitely less controversy and dispute, I suspect, than has hitherto so often prevailed on several questions of far less importance.

With your permission I will recur to the further illustration of the sulject in another communication.

Fitzroy-square, May, 1853. Your most obedient servant,

G. Milrox.

\section{MEDICAL SOCIETY OF LONDON.-TRACHEOTOMY IN EPILEPSY.}

To the Editor of The Lancet.

Sir,-Will you allow me space for a cursory reply to the remarks of Dr. Edwards, of Cheltenham, and Mr. Lıockhart Clarke, of Pimlico?

In the first place, I have to thank Dr. Edwards for the "entertainment" he has kindly furnished me, and at the same time to trespass upon his politeness by asking for a few additional particulars respecting his patient. In the meantime, I would venture to suggest that the practical value of his case would be more enhanced by attending to such ordinary matters as age, previous history, dates, and the like, than by punning upon the word "faith," or by substituting Greek for logic.

I do not for a moment deny that the violent and continued fits in Dr. Edwards' patient were caused by laryngismus, and relieved by tracheotomy. I only contend that no proof of this is given, or can be given in the time. What, for instance, is there to convince me, if I choose to be sceptical, that a paroxysm of fits of four hours and a half duration may not have been upon the point of terminating when the operation was performed, or that the stimulus of a scalpel may not have been sufficient to rouse the patient under these circumstances, and break the spell? And how am I to know that a comparatively fitless interval did not always and naturally succeed to these violent paroxyms. Doubts, such as these, would be unjustifiable if the fits hal alwass been vanquished by the operation, but as they have not, they are not only justifiable but inevitable.

I should also prefer proof to assertion before I agree to suppose that the fits continued in Dr. Andrea Verga's case, becanse the fistula was plugged up with mucus; and this the more, as Mr. Anderson's patient did happen to die in a true fit of epilepsy when her tube was perfectly open.

In the second place, I have to thank Mr. Lockhart Clarke for his po'ite communication, and to express my regret that I should in any degree bave misunderstood his statements. It is evident, however, that I have not erred very widels. It is evident, indeed, in the expression " somewhat different conclusion," that Mr. Clarke has not come to an opposite conclusion, for in the next paragraph he states that "the patient had derived but little benefit from the operation;" and a little further on he adds, that "the fits recurred and continued with about the same frequency and severity as before the operation." Without further evidence, also, I venture to imagine that $\mathrm{Mr}$. Clarke will not expect me to believe that any little improvement in the colour of the skir, and in the health generally, is to be ascribed to the operation, for, as he very well knows, such improvement is continually happening in all cases of epilepsy, whenever there is a lull in the symptoms, such as happened in the case in question.

I am compelled, also, to disallow the plea that Mr. Clarke's case was not a fair ose for testing the value of the remedy. This plea can scarcely be allowed where the operation is performed under Dr. Marshall Hall's sanction. It can scarcely be allowed on abstract grounds. Except so far as the continuance of the disease is concerned, it matters not ( so far as I can sre) how the "emotions and irritations" are called into play ; for whether originating in organic or functional mischief, they operate through the same nervous channels and agencies upon the muscles of the neck and larynx, and, exciting spasmodic laryngismus, cause convulsion, which convulsion and its effects are prevented by tracheotomy. This appears to be the theory. "By tracheotomy," says Dr. Marshall Hall, (The LA Nce.T, May 15, 1852,) "we cannot aroid the cause or causes, or their first effects, the slighter forms of the affection; but we can avoid the severer, the graver, the direr consequences of these causes. We can preserve the patient, as I have stated, not from falling, indeed, but from being dashed to the ground violently and convulsively; we can secure him from convulsion, and all its dire effects on the mind and on the limbs, and save him from mania, amentia, or paralysis." In a word, as Dr. Marshall Hall often says, spasmodic laryngismus is the essential condition of convulsion, and this convalsion is obviated by tracheotomy. The remote cause of the laryngismus merely affect the probabilities of cure. If this cause be irremediable, so is the laryngismus. If the cause be curable, so is the laryngismus. In either case, and equally, the convulsions are obviated by tracheotomy. I repeat, therefore, that, so far as I can see, the existence of organic and incurable mischief can furnish no valid explanation in any case of failure. On the contrary, I cannot understand why this very mischief should not be to the advantage of the operation rather than otherwise, for it would prevent the supposition that the improvement, consequent upon the operation, was due to any of those unaccountable and, as it were, spontaneous changes which not unfrequently cause the suspension of the fits in cases of mere functional epilepsy.

It only remains for me to ask the meaning of the expression" a noise, indicating the existence of laryngismus." Is this a stridulous inspiration on the passing off of the spasm, or what is it? I ask this question because it is of extreme importance to have all the aid we can in diagnosing this state of laryngismus, which, as occurring in epilepsy, seems to require no ordinary acumen to detect.

I have the honour to be, Sir, your obedient servant,

Henrietta-street, Cavendish-square, May, 1853. C. B. RadchIFFe, M.D.

\section{VACCINATION A'T GUY'S HOSPITAL. NOTE FROM DR. LEVER. To the Editor of The Lancer.}

SrR,- A letter appeared in your widely-eirculated journal of Saturday last, May 28th, headed "Neglect of Vaccination by Teachers," signed J. A. Hingeston, and dated from Brighton, in which he states that at the schcols of medicine in this metropolis, singling out St. George's and Guy's, there are no means of acquiring a knowledge of the method of vaccination, or of discriminating between a genuine and spurious vesicle.

Now, Sir, I will leave the St. George's professors to speak for themselves, but I will endeavour to rebut the broad assertions of your correspondent with regard to Guy's.

Mr. Hingeston states, "There is no vaccine ward in any of the London hospitals; there is no lecturer on vaccination; there are no drawings, diagrams, preparations or illustrations of the true vaccine vesicle, or, if such there be, it is a curiosity entirely accirlental. Vaccination may be appended to the lectures on midwifery."

Sir, it would be impossible to have a vaccine ward in our large metropolitan hospitals. Women with nursing children could not leave their homes and their domestic duties for the sake of having this supervision of the rise, progress, and decline of the vaccine vesicle; but to show that the matter has not been altogether neglected, I may mention that at Guy's Lying-in Charity, established nearly twenty years, every patient attended therefrom is told she may have her child vaccinated on a certain day and at certain hours, so that the pupils have the opportunity of seeing the mode of operation and witnessing the result, if the patient returns. A book has been kept from the commencement, recording name, residence, date and results; but the statistical data are far from satisfactory, as many women do not reappear. This plan was commenced by myself at the establishment of the Lying. in Charity, and continued to 1844 , from which time the daties have been performed by Mr. W. H. Petrigrew. It is true we have not now so many cases, as the parochial surgeons are paid, and deservedly paid, for the operation.

But surely drawings or engravings of the genuine appearances of the vaccine vesicle are to be found in all the libraries attached to our sebools, and to which students can at all times refer. With respect to preparations, it is absurd to suppose that we can have arms placed in jars for the purpose of inspection. It is rare for children to die during the development of vaccinia, and if affected by disease its progress is arrested, or its natural appearance changed.

Before making this sweeping assertion with respect to the want of illustrations in the museums attached to the schools, Mr. 